RUSSIAN ACADEMY OF SCIENCE

INSTITUTE FOR THE HISTORY OF MATERIAL CULTURE

SERGIEV POSAD STATE HISTORY

AND ART MUSEUM-PRESERVE

\section{SITE ZAMOSTJE 2}

\section{AND LANDSCAPE EVOLUTION \\ IN THE VOLGA-OKA REGION DURING THE HOLOCENE}


РОССИЙСКАЯ АКАДЕМИЯ НАУК

ИНСТИТУТ ИСТОРИИ МАТЕРИАЛЬНОЙ КУЛЬТУРЫ

СЕРГИЕВО-ПОСАДСКИЙ ГОСУДАРСТВЕННЫЙ

ИСТОРИКО-ХУДОЖЕСТВЕННЫЙ МУЗЕЙ-ЗАПОВЕДНИК

\section{СТОЯНКА ЗАМОСТЬЕ 2}

И РАЗВИТИЕ ПРИРОДНОЙ СРЕДЫ ВОЛГО-ОКСКОГО МЕЖДУРЕЧЬЯ В ГОЛОЦЕНЕ 


\section{Рецензенты:}

доктор исторических наук В.Е. Щелинский доктор исторических наук М.Г. Жилин доктор исторических наук А.А. Выборнов

\section{Ответственньй редактор:}

к.и.н. О.В. Лозовская

\section{Составители:}

к.и.н. О.В. Лозовская,

к.и.н. В.М. Лозовский

С829 Стоянка Замостье 2 и развитие природной среды Волго-Окского междуречья в голоцене: Коллективная монография / Сост. О.В. Лозовская, В.М. Лозовский. - СПб: ИИМК РАН, 2018. - 214 с.: ил.

ISBN 978-5-9909872-8-9

Коллективная монография является результатом комплексных исследований палеоландшафта и условий обитания населения мезолита и неолита в бассейне Верхней Волги на примере известного озерного поселения Замостье 2 (Сергиево-Посадский р-н Московской области). Для реконструкции растительности и рельефа территории, окружавших стоянку в среднем и позднем голоцене, привлечены данные палинологических, палеоботанических и антракологических исследований, результаты метода геохимической индикации, а также археологические и исторические архивные источники.

Предназначена для специалистов археологов, историков, палеоботаников, специалистов смежных дисциплин и широкого круга читателей.

\section{УДК 902/904}

ББК 20,1

63.4

Для обложки использованы фотографии В.М. Лозовского и О.В. Лозовской: река Дубна в районе стоянки Замостье 2, 1997; сосновая шишка из слоя мезолита, 2013 


\section{ОГЛАВЛЕНИЕ CONTENTS}

О.В. Лозовская

Введение

Olga Lozovskaya

Introduction.

ГЛАВА 1

О.К. Борисова

Развитие растительности на верхневолжской низменности

и прилегающих возвышенностях в голоцене: реконструкция по палеоботаническим данным

Olga Borisova

Vegetation development on the Upper Volga lowland

and the adjacent uplands in the Holocene: reconstruction based on paleobotanical data.

ГЛАВА 2

Е.Г. Ершова, О.В. Лозовская

Природное окружение мезолитических и неолитических стоянок Замостье 2

по данным ботанического и спорово-пыльцевого анализа

Ekaterina Ershova, Olga Lozovskaya

Paleoenvironment of Mesolithic and Neolithic settlements at Zamostje 2

according to botanical and pollen analysis.

\section{ГЛАВА 3}

Marian Berihuete

First results of the archaeobotanical study of the Test pit 2 Profile column

M. Бериуэте

Первые результаты археоботанического

изучения колонки из разреза шурфа 2

ГЛАВА 4

А.Л. Александровский

Первые результаты определений породы деревьев по древесному углю из слоев мезолита. Замостье 2

Alexandre Alexandrovskiy

The first results of the trees species determination on the charcoal from the Mesolithic layers. Zamostje 2

ГЛАВА 5

М.А. Кулькова

Условия осадконакопления в раннем голоцене на стоянке Замостье 2

по данным радиоуглеродного и геохимического анализов

Marianna Kulkova

Process of sedimentation during Early-Middle Holocene on the Zamostje 2 site

basing on the data of radiocarbon and geochemical analysis.

ГЛАВА 6

Charlotte Leduc, Louis Chaix

Animal exploitation during Mesolithic and Neolithic occupations at Zamostje 2 (Russia):

preliminary results and perspectives of research

Ш. Ледюк, Л. Ше

Эксплуатация животных на мезолитических и неолитических поселениях в Замостье 2:

предварительные результаты и перспективы исследования 


\section{ГЛАВА 7}

О.В. Лозовская, В.М. Лозовский (†)

Природная среда и условия обитания в позднем мезолите и неолите

на поселении Замостье 2

Olga Lozovskaya, Vladimir Lozovski $(\dagger)$

Environment and subsistence conditions in Late Mesolithic and Neolithic at site Zamostje 2

ГЛАВА 8

Н.А. Кренке, Е.Г. Ершова, А.А. Войцик, А.К. Каспаров, М.В. Лавриков, В.А. Раева

Археологическая разведка в нижнем течении р. Сулать

(к вопросу об изменении ландшафтов и истории хозяйственного освоения

региона Заболоцкого озера в позднем голоцене)

Nikolay Krenke, Ekaterina Ershova, Andrey Voitsik, Alexey Kasparov, Mikhail Lavrikov, Vera Raeva

Archaeological reconnaissance at the mouth of Sulat' River

(the study of landscape dynamic and history of land-use within Zabolotskoe lake in late Holocene)

ГЛАВА 9

Б.В. Кудрявиев

Населенные пункты и прилегающая к ним местность в районе Заболотского озера

и правобережья реки Дубны в XVI-XVIII веках: историческая справка

Boris Kudryavtsev

Settlements and adjacent areas in the region of the Zabolotskoye lake and right bank

of the Dubna River in XVI-XVIII centuries: historical reference.

ПРИЛОЖЕНИЕ 1

Э.А. Крутоус

Палеоботаническое изучение и палеогеографические реконструкции стоянки «Замостье»

Eleonora Krutous

Paleobotanical studies and paleogeographic reconstructions of site Zamostje 2

Список сокращений.

Об авторах. 


\title{
ГЛАВА 4
}

\section{ПЕРВЫЕ РЕЗУЛЬТАТЫ ОПРЕДЕЛЕНИЙ ПОРОДЫ ДЕРЕВЬЕВ ПО ДРЕВЕСНОМУ УГЛЮ ИЗ СЛОЕВ МЕЗОЛИТА. ЗАМОСТЬЕ 2}

\author{
А.Л. Александровский
}

\section{THE FIRST RESULTS OF THE TREES SPECIES DETERMINATION ON THE CHARCOAL FROM THE MESOLITHIC LAYERS. ZAMOSTJE 2}

Alexandre Alexandrovskiy

\section{ВВЕДЕНИЕ}

Методы определения породы деревьев по уголькам (антракология) при изучении археологических объектов России применяются в очень редких случаях. Вместе с тем, метод активно развивается, получены первые результаты и по объектам на территории нашей страны (Ponomarenko, Anderson, 2013; Пономаренко и др., 2015). Проведение подобных исследований, особенно совместно с палинологическими, позволяют получить более полное представление об изменениях растительного покрова в голоцене. Кроме того, данные антракологии дают возможность более определенно охарактеризовать деятельность человека, особенно, если имеются образцы угля из культурного слоя и отдельных археологических объектов, например, очагов и сгоревших построек.

Памятник Замостье 2 является многослойным озерным поселением позднего мезолита - неолита (Лозовский, Лозовская, 2014a). Угли были отобраны в процессе раскопок в 1995-2000 гг. Позже в шурфе 2013 г. были взяты образцы для палинологического анализа, проведенного Е.Г. Ершовой (2013), и для исследования вещественного состава отложений (Александровский, 2014a).

Первая партия образцов древесного угля, относящаяся к мезолиту, примерно по 50 фрагментов угля из четырех слоев мезолита (всего 197 фрагментов), была предоставлена О.В. Лозовской автору для определений в 2015 г. Результаты оказались интересными и в связи с этим были определены все мезолитические угли, общим количеством 884. Полученные результаты определения пород деревьев по уголькам являются, вероятно, первыми для слоев мезолита озерно-болотных памятников на территории Европейской России. Поэтому сравнивать их можно только с палинологическими данными, имеющимися по данному памятнику (Замостье 2) и другим сходным объектам (Ершова, 2013). Кроме того, для сравнения можно использовать полученные нами ранее результаты исследования углей из близких по возрасту, но, все же, более молодых ранненеолитических слоев поселений на Сертее, в Смоленской области (Александровский, 20146).

\section{ОБЪЕКТЫ И МЕТОДЫ}

По данным многолетних исследований установлено, что культурные слои мезолита и неолита на месте памятника Замостье 2 залегают в слоях сапропеля и торфа на глубине более 2,5 м (Лозовский, Лозовская, 2014a). В раскопе II с поверхности залегает слоистая супесь мощностью около 1 м (отвал XX в.), ниже, до 170 см, торф с находками средневековья, еще ниже до 230 см, суглинок суббореальной трансгрессии. Ниже, под тонким слоем торфа (230-240 см) с находками льяловской культуры (средний неолит), залегают сапропели. На глубине 240-257 см в темном сапропеле с обилием мелких древесных остатков лежат материалы верхневолжской культуры (ранний неолит), встречаются угольки. Ниже (257-266 см) в сапропеле с высоким содержанием обломков тонких и средних веток сделаны находки, предварительно отнесенные к финальному мезолиту (ФМ/FM). Под горизонтом оливкового сапропеля (266275 см) без находок и древесных остатков, лежат два горизонта (275-301 см) темного сапропеля с угольками, большим количеством коры, веток, щепы, и остатками верхнего мезолитического слоя (BM/LM UL). Ниже следует серый сапропель с малым количеством находок того же времени (301-311 см). На глубине 311-326 см залегает горизонт серого сапропеля с изобилием щепы, веток, коры, имеются угли. В нем залегает нижний мезолитический слой (HМ/ LM LL) (Лозовский, Лозовская, 2014a).

Сходные слои выявлены в шурфе 2013 г. Сапропель, слагающий здесь нижнюю часть озерно-болотной толщи, характеризуется слабощелочной реакцией, повышенным содержанием карбонатов, а также фосфора, особенно в пределах слоев мезолита и раннего неолита (Алексан- 
Таблица 1. Замостье 2. Результаты определения углей (для сравнения приведены данные по Сертее II, см. Александровский, 20146).

Table 1. The results of charcoal studies (for comparison with the data from Serteya II, sеe Александровский, 20146).

\begin{tabular}{|c|c|c|c|c|c|c|c|c|c|c|c|c|c|c|c|c|c|c|}
\hline $\begin{array}{l}\text { Объект, } \\
\text { образец }\end{array}$ & 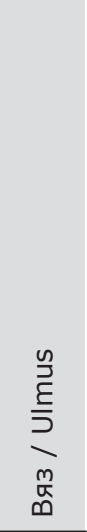 & $\begin{array}{l}\frac{1}{ \pm} \\
\frac{U}{4} \\
\frac{1}{ \pm} \\
\frac{1}{5} \\
\underline{1}\end{array}$ & 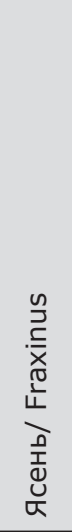 & 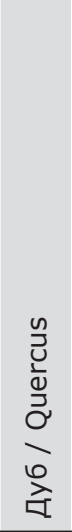 & 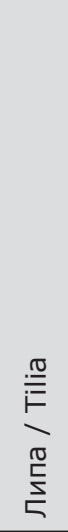 & 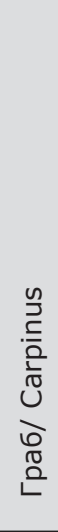 & 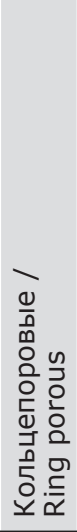 & 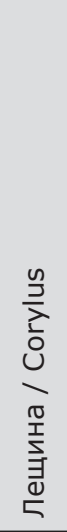 &  & 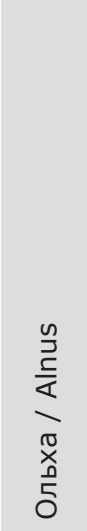 & 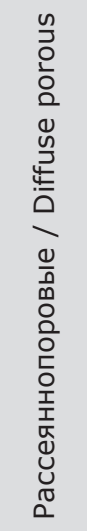 & 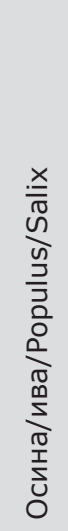 & 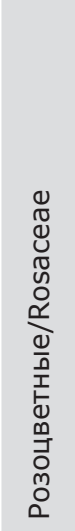 & 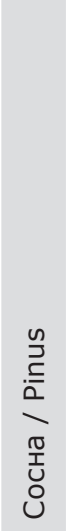 & 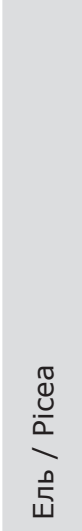 &  & 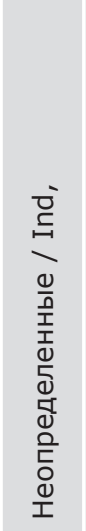 & 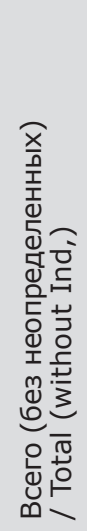 \\
\hline $\begin{array}{l}\text { Сл, } 5 \text { ФМ / } \\
\text { FM, layer } 5\end{array}$ & $\begin{array}{c}79 \\
30,7\end{array}$ & $\begin{array}{l}16 \\
6,2 \\
\end{array}$ & & & $\begin{array}{l}21 \\
8,2 \\
\end{array}$ & & & $\begin{array}{c}1 \\
0,4 \\
\end{array}$ & $\begin{array}{c}32 \\
12,4 \\
\end{array}$ & $\begin{array}{c}31 \\
12,1 \\
\end{array}$ & $\begin{array}{c}59 \\
23,0\end{array}$ & $\begin{array}{c}4 \\
1,6 \\
\end{array}$ & $\begin{array}{c}3 \\
1,2 \\
\end{array}$ & $\begin{array}{c}6 \\
2,3 \\
\end{array}$ & & $\begin{array}{c}5 \\
1,9 \\
\end{array}$ & $(5)^{*}$ & 257 \\
\hline $\begin{array}{c}\text { Сл, } 7 \text { ВM / } \\
\text { LM-UL, layer } \\
7\end{array}$ & $\begin{array}{c}58 \\
18,4\end{array}$ & $\begin{array}{l}17 \\
5,4\end{array}$ & & & $\begin{array}{l}19 \\
6,0\end{array}$ & & $\begin{array}{c}1 \\
0,3\end{array}$ & $\begin{array}{c}1 \\
0,3\end{array}$ & $\begin{array}{c}50 \\
15,9\end{array}$ & $\begin{array}{c}44 \\
14,0\end{array}$ & $\begin{array}{l}108 \\
34,3\end{array}$ & $\begin{array}{c}2 \\
0,6\end{array}$ & $\begin{array}{c}5 \\
1,6\end{array}$ & $\begin{array}{c}2 \\
0,6\end{array}$ & $\begin{array}{c}1 \\
0,3\end{array}$ & $\begin{array}{c}7 \\
2,2\end{array}$ & (8) & 315 \\
\hline $\begin{array}{c}\text { Сл, } 8 \text { ВМ / } \\
\text { LM-UL, layer } \\
8\end{array}$ & $\begin{array}{c}17 \\
15,3\end{array}$ & $\begin{array}{c}13 \\
11,7\end{array}$ & & & $\begin{array}{l}11 \\
9,9\end{array}$ & & $\begin{array}{c}1 \\
0,9\end{array}$ & & $\begin{array}{c}27 \\
24,3\end{array}$ & & $\begin{array}{c}37 \\
33,3\end{array}$ & $\begin{array}{c}2 \\
1,8\end{array}$ & $\begin{array}{c}1 \\
0,9\end{array}$ & & & 2 & (3) & 111 \\
\hline $\begin{array}{c}\text { Сл, } 9 \text { НM / } \\
\text { LM-LL, layer } \\
9\end{array}$ & $\begin{array}{c}8 \\
14,3\end{array}$ & $\begin{array}{c}10 \\
17,9\end{array}$ & & & $\begin{array}{c}5 \\
8,9\end{array}$ & & & & $\begin{array}{c}11 \\
19,6\end{array}$ & $\begin{array}{c}1 \\
1,8\end{array}$ & $\begin{array}{c}17 \\
30,4\end{array}$ & $\begin{array}{c}4 \\
7,1\end{array}$ & & & & & $(2)$ & 56 \\
\hline $\begin{array}{c}\text { Сл, } 10 \text { HM / } \\
\text { LM-LL, layer } \\
10\end{array}$ & $\begin{array}{c}24 \\
19,3\end{array}$ & $\begin{array}{l}10 \\
8,1\end{array}$ & & ${ }_{1,6}^{2}$ & $\begin{array}{l}11 \\
8,9\end{array}$ & & & & $\begin{array}{c}27 \\
21,8\end{array}$ & & $\begin{array}{c}\mathbf{4 6} \\
37,1\end{array}$ & $\begin{array}{c}4 \\
3,2\end{array}$ & & & & & (4) & 124 \\
\hline $\begin{array}{l}\text { Замостье } 2 \\
\text { Zamostje } 2\end{array}$ & 186 & 66 & & 2 & 67 & & 2 & 2 & 147 & 76 & 267 & 16 & 9 & 8 & 1 & 14 & $(21)$ & 863 \\
\hline$\%$ & 21,6 & 7,6 & & 0,2 & 7,8 & & 0,2 & 0,2 & 17,0 & 8,8 & 30,9 & 1,9 & 1,0 & 0,9 & 0,12 & 1,6 & & \\
\hline $\begin{array}{l}\text { Сертея II } \\
\text { Serteya II }\end{array}$ & 344 & 149 & 115 & 170 & 16 & 40 & - & 59 & 18 & 662 & 270 & 28 & 4 & 46 & 113 & 65 & & 1963 \\
\hline$\%$ & 17,5 & 7,6 & 5,9 & 8,7 & 0,8 & 2 & - & 3 & 0,9 & 33,7 & 13,8 & 1,4 & 0,2 & 2,3 & 5,8 & 3,3 & & \\
\hline
\end{tabular}

*Неопределенные при подсчетах не учитывались

дровский, 2014a). Также для сапропеля по данным анализов характерно высокое содержание органического вещества, о том же свидетельствуют изобилие растительных остатков разной степени разложенности. Выше сапропель сменяется торфом, для которого характерны кислые и слабокислые значения $\mathrm{pH}$, отсутствие карбонатов, низкое содержание фосфора и максимально высокое содержание органического вещества.

Для анализа угля использовались все фрагменты, которые отбирались из всего слоя, причем угли из очагов, как это предлагают (Хейнц, 2001; Badal, 1990), не отбрасывались. Это связано с тем, что угли, рассеянные в слое, а именно только их предлагают исследовать названные авторы, являются производными от всех углей, в том числе, от очагов, а также от строительной и поделочной древесины, сгоревшей в пожарах. Поэтому все угли, отобранные в слое, имеют одни и те же источники и в равной степени характеризуют состав древесного материала, принесенного человеком на место памятника, и наиболее полно сохранившегося в виде углей.

\section{РЕЗУЛЬТАТЫ}

Всего проведены определения по 863 обломкам угля, в количестве от 111 до 315 в каждом из четырех основных мезолитических слоев и 56 - в дополнительном слое 9 (табл. 1). В целом полученные результаты достаточно репрезентативные, и на основе их сравнительного анализа можно проводить реконструкции природной среды. С целью сопоставления данных все подсчитанные угольки были условно разделены на три группы пород деревьев: широколиственные, мелколиственные и хвойные.

Наиболее четко по строению древесной ткани отделяются хвойные. В целом, доля хвойных невелика, менее $3 \%$. При этом определить породы хвойных удается не всегда. В 35\% случаев это сосна, ель единична, среди остальных хвойных (неразделенных) несомненно преобладает сосна, но сохранность и величина фрагментов не позволяют сделать более точные определения.

В состав широколиственных входят кольцепоровые (кольцесосудистые), которые определяются четко. В иссле- 
дованных образцах из Замостья 2 они представлены почти исключительно вязом. Вместе с небольшим количеством дуба и кольцепоровых неразделенных они преобладают (190 фрагментов). Частично в состав широколиственных входят рассеяннопоровые. В Замостье 2 это клен и липа, которых выявлено 133. Всего определено 325 фрагментов древесины широколиственных.

Мелколиственные все относятся к рассеяннопоровым. В Замостье 2 выявлены угли березы, осины и ивы в количестве 163 фрагмента. Также к ним должна относиться и основная часть от 267 фрагментов рассеяннопоровых неразделенных. Отметим, что часть этой группы, но не более $20 \%$, может принадлежать клену и липе. В итоге количество широколиственных и мелколиственных примерно равно: первых 325-350, вторых 400-415 фрагментов.

Полученные результаты анализа углей дают возможность ориентировочно представить состав лесов, окружавших Замостье 2 на разных этапах мезолита. Результаты даются по четырем основным слоям (стратиграфия и возраст по Лозовский, Лозовская, 2014a):

1. слой финального мезолита 7100-6900 ВР, или 5970-5760 cal BC;

2. верхняя часть верхнего мезолитического слоя 7200 $7100 \mathrm{BP}$;

3. нижняя часть верхнего мезолитического слоя 7400$7300 \mathrm{BP}$;

4. нижний слой мезолита - даты 7900-7800 ВР, 70006600 cal BC (по Lozovski, 1996, по нашим данным 6730$6630 \mathrm{BC})$;

также выделяется слой 9, занимающий промежуточное положение между слоями 3 и 4.

В целом протяженность времени формирования 4-х данных слоев 1000-1200 лет.

\section{ОБСУЖДЕНИЕ}

Состав пород по профилю относительно ровный, доминирующими породами являются: вяз, береза, клен, липа и ольха (табл. 1). Остальных пород значительно меньше. В числе углей, отнесенных к ольхе, может в небольшом количестве присутствовать имеющая сходные ложные лучи лещина. Однако на процентном соотношении мелко- и широколиственных пород это практически не сказывается.

Данные, приведенные в таблице 1 , показывают, что в составе угольного пула преобладает вяз - 21,6\%. Особенно много его в слое 5, времени финального мезолита - 30,7\%. Березы несколько меньше $(17,0 \%)$, но если учесть, что на березу приходится значительная доля от числа рассеяннопоровых неразделенных, то ее доля увеличивается почти вдвое, и преобладающей является она. Это вполне объяснимо, так как разрез располагается в прибрежной заболоченной зоне палеоозера, а именно для таких условий характерны заросли березы. Для подобных прибрежных местообитаний столь же характерны ива и ольха. Последняя появляется в районе Замостье 2 в период верхнего мезолита и вскоре распространяется достаточно широко (до 13,6\%). Соответственно снижается доля березы (с 23,7 до $12-15 \% \%)$. Неожиданным является практически полное отсутствие дуба среди довольно большой группы широколиственных. Не менее удивительна очень низкая доля хвойных, в том числе, сосны, которой много по данным палинологии и определения образцов древесины (колья от мезолитических сооружений).

По сравнению с современностью в проанализированных слоях мезолита значительно выше доля углей широколиственных, меньше мелколиственных (преимущественно, вторичных) и, особенно, хвойных пород. Ранее еще более высокое содержание широколиственных нами было обнаружено при исследовании слоев раннего неолита сходного озерно-болотного памятника Сертея II (Александровский, 20146).

Данные антракологии отличаются от результатов определения древесины (Лозовская, Лозовский, 20146). Среди последних представительными являются данные по вертикальным кольям из русла реки и по деревянному инвентарю из нижнего и верхнего мезолитических слоев. Отметим также, что остатки древесины были отобраны и результаты их определения приведены на диаграммах по отдельным функциональным группам (колья, инвентарь, верши). Поэтому, видовой состав деревьев здесь отражает предпочтения человека в использовании той или иной породы, и, в меньшей степени, позволяет представить общий состав окружающей растительности.

Наиболее ярким отличием для остатков древесины является значительное присутствие хвойных (причем, в верхнемезолитическом слое их 50\%), очень слабо представленных по данным антракологии. Несколько меньше среди них доля широколиственных, но также как и для углей, преобладает вяз. Почти полностью отсутствует липа, что особенно странно для остатков инвентаря. Отметим также, что в составе кольев выявлено высокое содержание граба (по нашему мнению, этот факт требует дальнейших исследований).

Доминирование углей вяза и отсутствие дуба и ясеня в слоях мезолита на Замостье 2 вероятно является особенностью состава древесных пород в окрестностях данного места. Это отличает их от неолитических слоев Сертеи (Александровский, 2014), а также от других объектов, изученных в центре Русской равнины, для которых имеются антракологические данные по различным периодам голоцена. В частности, на территории Москвы, высокое содержание углей дуба и ясеня обнаружено на городище РЖВ в Дьяково, заметно их присутствие и в ранних средневековых слоях в центре Москвы (Александровский 2012; Александровский и др., 2015). По сравнению с другими объектами, в мезолитических слоях Замостья значительно выше доля березы и липы (табл. 1).

По сравнению с данными палинологии, (Алешинская и др., 2001; Ершова, 2013), антракология показывает более высокое содержание остатков широколиственных во всех слоях, как в более ранних (нижний мезолитический слой), так и в поздних (финальный мезолитический слой). При этом, если доля хвойных необычно мала, то доля березы достаточно высокая, хотя и меньше, чем по пыльцевым данным.

Соответствует пыльцевым данным (Алешинская и др., 2001; Ершова, 2013) достаточно высокое участие среди широколиственных углей липы. При этом, клен, достаточно широко представленный во всех образцах угля, по данным анализа пыльцы отсутствует. В отличие от пыльцевых данных, участие ольхи очень низкое. В нижних слоях мезолита угли ольхи вообще отсутствуют и появляются в поздних слоях, но, в целом, в небольших количествах.

Пока не ясно, отражают ли приведенные различия по углям между слоями мезолита на Замостье 2 какие-то закономерности в развитии растительности в среднем голоцене, либо эти различия связаны с локальными условиями развития ландшафтов. Если следовать полученным данным, обнаруживается постепенное увеличение во времени присутствия вяза, липы и ольхи. Климатические условия времени мезолита представляются, не только, как более теплые, но и как менее влажные, чем современные. 
Процентное содержание тех или иных пород отчасти свидетельствует о дальности расположения соответствующих древостоев в прошлом. Если следовать данным антракологии, то в непосредственной близости от Замостья 2 в мезолите произрастали вяз, липа, клен, береза. Наоборот, древостои сосны, дуба, ясеня и некоторых других пород располагались на удалении. Полученные данные также свидетельствуют о том, что в непосредственной близости от поселений преобладали растительные группировки, произраставшие в нормальных автономных эдафических условиях. Болотная растительность, выявляющаяся по данным палинологии и других методов (Ершова, 2013), вероятно была развита непосредственно в субаквальных условиях. Кроме болотных велика доля представителей наземных трав (полынь, маревые), которые можно отнести к рудеральным или степным видам, а также имеется комплекс древесной растительности, которая может быть охарактеризована, как водораздельная (Ершова, 2013).

Возникает вопрос, где эта растительность произрастала? Водоразделы располагаются далеко. Возможно, эта растительность произрастала в днище озерной котловины, на гривах и других повышениях рельефа. По данным наших комплексных почвенно-палинологических исследований в пойме Москвы-реки, лесная растительность, близкая по облику к водораздельной, и соответствующие ей хорошо развитые лесные почвы - дерново-подзолистые и серые лесные, а под остепненными лугами в среднем голоцене - лугово-черноземные, занимали большие пространства в днище долины (Кренке и др., 2014; Ershova et al., 2015). В почвоведении подобные условия и соответствующие им почвы, в отличие от гидроморфных, называются мезоморфными. В отличие от ксероморфных они обводнены, но уровень грунтовых вод располагается всегда глубже, чем в гидроморфных условиях, и на таких почвах могут произрастать растительные группировки, вполне соответствующие водораздельным. Эти почвы сходны с автономными, но в нижней части профиля оглеены. Видимо именно в таких условиях обитали лесные группировки времени мезолита в районе Замостья 2. Кроме них, по данным палинологии, там же существовали и открытые пространства, с заметным участием рудеральных (степных) видов. Гидроморфные условия были распространены локально вдоль берега озера.

По нашему мнению, некоторое сходство с условиями среды мезолита Замостья 2 могут иметь расположенные южнее современные ландшафты в долине р. Пра, протекающей через систему озер (оз. Великое и др.). Пойма реки и днище этой озерной котловины заняты широколиственными лесами, представленными, в основном, дубом и липой. Пойменные дубравы характерны для среднего течения Оки, например, в пределах озерного расширения поймы у Спасска-Рязанского. Для времени мезолита в Замостье стабильные условия, благоприятствующие произрастанию растительности, сходной с водораздельной, в днищах долин были более характерны, чем для современности. При этом, широколиственные, особенно вяз, в составе ценозов участвовали в большей степени, а также присутствовали степные растительные группировки.

Антракологические данные по Сертее показывают дифференцированное использование пород деревьев в раннем неолите. В пойме р. Сертейки (приток Западной Двины) использовались произраставшие здесь вяз, ольха и другие широко- и мелколиственные породы, на окружающих террасах, сложенных песками - почти исключительно сосна (Александровский, 20146). В Замостье неоднородность растительного покрова выражена слабее, так как долина здесь более широкая и влияние внедолинной растительности на антракологические спектры внутренней части котловины здесь невелико.

Сделанные выводы высказываются как предварительные. Исследован интервал времени, продолжительностью 1000 лет, относящийся к началу атлантического периода. Необходимо продолжение исследований, увеличение числа определений, как по самому времени мезолита, так и по другим слоям озерно-болотных отложений. Только на основе сравнительного анализа пыльцевых, антракологических и палеопочвенных данных можно выйти на новый уровень понимания специфики природных условий мезолитической эпохи в данном районе.

\section{БНБЛИОГРАФИЯ}

Александровский А.Л. 2014а Запись среды в озерноболотных отложениях памятника Замостье 2 // B.M. Лозовский, О.В. Лозовская (ред.) Природная среда и модели адаптации озерных поселений в мезолите и неолите лесной зоны Восточной Европы. СПб: ИИМК РАН, 2014. C. 54-57.

Александровский А.Л. 20146 Естественнонаучные исследования на археологических памятниках Сертеи. Почвы, антракология // А. Мазуркевич, М. Полковникова, Е. Долбунова (ред.) Археология озерных поселений IV-II тыс. до н. э.: хронология культур и природно-климатические ритмы. Материалы международной конференции, 13-15 ноября 2014. СПб: Периферия, 2014. С. 134-146.

Александровский А.Л., Александровская Е.И. 2012 Естественнонаучные исследования на археологических памятниках Москвы // Археология Москвы - линия жизни. Сб. статей и материалов. М.: Т-Принт Групп. 2012. С. 94-105.

Александровский А.Л., Векслер А.Г., Александровская Е.И., Риль С. 2015 Ильинка. Исследования почв и культурного слоя Москвы методами естественных наук // Приложение в книге: А.Г. Векслер. Москва. Раскопки на Великом посаде. Улица Ильинка, Биржевая площадь, Старый Гостиный двор. Материалы исследований. М.: ТМ Продакшн, 2015. С. 371-381.

Алешинская А.С., Лаврушин Ю.А., Спиридонова Е.А. 2001 Геолого-палеоэкологические события голоцена и среда обитания древнего человека в районе археологического памятника Замостье 2 // Каменный век европейских равнин: объекты из органических материалов и структура поселений как отражение человеческой культуры. Материалы международной конференции, Сергиев Посад, 1-5 июля 1997 г. Сергиев Посад: Подкова, 2001. С. 248-254.

Ершова Е.Г. 2013 Результаты ботанического и спорово-пыльцевого анализа по разрезам стоянки Замостье 2, 2013 г. // В. Лозовский, О. Лозовская, И. Клементе Конте (ред.) Замостье 2. Озерное поселение древних рыболовов эпохи мезолита-неолита в бассейне Верхней Волги. СПб.: ИИМК РАН, 2013. С. 181-192.

Кренке Н.А., Ершова Е.Г., Александровский А.Л. 2014 Природные и антропогенные ландшафты в долине Москвы-реки по материалам комплексного исследования 1-й Звенигородской неолитической стоянки //Известия РАН. Серия географическая. № 5. 2014. С. 99-115.

Лозовский В.М., Лозовская О.В. 2014а. Стратиграфия отложений и культурных слоев стоянки Замостье 2 // В.М. Лозовский, О.В. Лозовская (ред.) Природная среда и модели адаптации озерных поселений в мезолите и неолите лесной зоны Восточной Европы. СПб.: ИИМК РАН, 2014. C. $46-53$. 
Лозовская О.В., Лозовский В.М. 20146 Использование древесины в позднем мезолите - раннем и среднем неолите на озерном поселении Замостье 2 // В.М. Лозовский, О.В. Лозовская (ред.) Природная среда и модели адаптации озерных поселений в мезолите и неолите лесной зоны Восточной Европы. СПб.: ИИМК РАН, 2014. C. 64-69.

Пономаренко Е.В., Пономаренко Д.С., Сташенков Д.А., Кочкина А.Ф. 2015 Подходы к реконструкции динамики заселения территории по почвенным признакам // Поволжская Археология. № 1. 2015. С. 126-150.

Хейнц К. 2001 Методы исторической антракологии: отбор образцов при раскопках и интерпретация данных // Каменный век европейских равнин: объекты из органических материалов и структура поселений как отражение человеческой культуры: материалы международной конференции, Сергиев Посад, 1-5 июля 1997 г. Сергиев Посад: Подкова, 2001. С. 242-247.
Badal Garcia E. 1990. Aportaciones de la antracología al estudio del paisaje vegetal y su evolución en el Cuaternario reciente, en la costa mediterránea del País Valenciano y Andalucía (18.000-3.000 BP). Tesis doctoral, Universitat de Valencia, $258 \mathrm{p}$.

Ershova E.G., Alexandrovskiy A.L., Krenke N.A., Korkishko D.V. 2016 New pollen data from paleosols in the Moskva River floodplain (Nikolina Gora) // Natural and anthropogenic environmental changes during the Holocene. Quaternary International, 420. P. 294-305.

Lozovski V.M. 1996. Zamostje 2. Les derniers chasseurspêcheurs préhistoriques de la Plaine Russe. Guides archéologiques du Malgré-Tout. Treignes: CEDARC. 96 p.

Ponomarenko E., Anderson D.W. 2013 Signature of forest fires in prairie soils // Charcoal and microcharcoal. Continental records / F. Damblon ed. Proceedings of the 4th International Meeting of Anthracology. BAR International Series 2486. Oxford: Archaeopress, 2013. P. 195-202. 